\title{
Notas Sobre as Bases da Formação Socioespacial Latino-americana
}

\author{
Notes on the Bases of Latin American Socioespacial Formation
}

\begin{abstract}
João Vitor Sandri Coelho
Graduado em Geografia pela Universidade Federal de Santa Catarina - UFSC, Brasil

jvsandri09@gmail.com
\end{abstract}

Edson de Morais Machado

Doutorando PPGGeo UFSC

Professor do Instituto Federal Catarinense - Campus Blumenau, Brasil

Edsonmachado1988@hotmail.comr

\begin{abstract}
Resumo
Através do referencial teórico-metodológico da Teoria da Dualidade Básica (Ignácio Rangel), buscase com este artigo investigar o desenvolvimento econômico e social da América Latina a fim de explorar a potencialidade explicativa da teoria rangeliana e validá-la como meio para uma análise rigorosa da formação socioespacial latino-americana, em alternativa às perspectivas circulacionistas e cepalinas. Os principais resultados apontam para a superação, por parte da Teoria da Dualidade, das perspectivas circulacionistas/dependentistas que atribuem foco central nas externalidades, através de uma análise que engendra tanto a esfera da produção quanto da circulação. Bem como supera os modelos cepalinos que se atém a visão nada dialética da contínua reprodução do arcaico em antagonismo ao moderno, e explicita a progressividade da história sob a especificidade de um desenvolvimento desigual e combinado da periferia do sistema capitalista.
\end{abstract}

Palavras-chave: América Latina. Formação Socioespacial. Teoria da Dualidade.

\begin{abstract}
Through the theoretical-methodological reference of the category of the Theory of Basic Duality (Ignácio Rangel), this article seeks to investigate the economic and social development of Latin America in order to explore the and to validate it as a means for a rigorous analysis of the sociospatial formation in Latin America, as an alternative to the interpretations from Cepal and Dependence Theory. The main results point to the overcoming, on the part of the duality theory, of the circulacionistas / dependentistas perspectives that assign central focus in the externalities, through an analysis that engenders both the sphere of the production as of the circulation. As well as surpassing the Cepal's models, one holds to the dialectical view of the continuous reproduction of the archaic in antagonism to the modern, and makes explicit the progressivity of history under the specificity of an uneven and combined development of the periphery of the capitalist system.
\end{abstract}

Keywords: Latin America. Socio-spatial formation. Theory of Duality. 


\section{INTRODUÇÃO}

Como afirma o professor Armen Mamigonian em sua recente obra Visão geográfica do Brasil atual: estado, crises e desenvolvimento regional (MAMIGONIAN, 2018), uma das grandes descobertas de Humboldt foi a de perceber que "a realidade concreta se organiza a partir de dois sistemas, que se completam, o sistema natural e o sistema social”, isto é, os paradigmas de geossistema e de formação social, ambos caros à geografia ${ }^{1}$. O primeiro já se encontra com bom grau de aceitação dentro da academia, diferentemente do segundo que, por sua raiz marxista, enfrenta certa resistência. Neste sentido, o economista Ignácio Rangel se apresenta como um dos poucos autores capazes de utilizar de forma rigorosa as categorias próprias do materialismo histórico, tais como modo de produção $(\mathrm{RP}+\mathrm{FP}$; superestrutura + infraestrutura) e formação social — definido como a combinação de modos de produção, isto é, forças produtivas e relações de produção específicas —, enquanto instrumento para decifrar o Brasil e a América Latina, distanciando-se da interpretação dependentista em que leva em consideração apenas os fatores externos enquanto determinante do complexo processo de desenvolvimento econômico. Deste modo, o presente artigo busca explorar o debate teórico referente à formação socioespacial da América Latina, tendo como base a Teoria da Dualidade Básica (Ignácio Rangel).

\section{A COMBINAÇÃO TEÓRICA ENTRE A CATEGORIA DE FORMAÇÃO SOCIOESPACIAL E A TEORIA DA DUALIDADE BÁSICA}

A categoria de formação socioespacial se constitui como um derivado da categoria marxiana de formação social, da qual foi amplamente aprofundada por Lenin em sua análise sobre a Rússia, em O Desenvolvimento do capitalismo na Rússia. Por meio da análise da evolução histórica de diversos países e regiões, K. Marx observou a existência de leis de desenvolvimento comuns a todos eles. Destacando as relações de produção (relação homem - homem) e as forças produtivas (relação homem - natureza) $)^{2}$, o intelectual alemão caracterizou os modos de produção comunistas primitivos, escravistas, feudais, capitalistas e socialistas.

\footnotetext{
${ }^{1}$ Segundo a professora Raquel Pereira: "De um lado, existe a fisionomia natural da Terra e seus esquemas de transformação que precisam ser compreendidos e explicados, considerando-se que, entre os agentes modeladores, entre os elementos da paisagem, encontram-se os homens. De outro lado, estão as sociedades humanas que devem ser compreendidas e explicadas, levando-se em conta que, entre as condições da sua estrutura e evolução, encontram-se o relevo, a hidrografia, a localização, o clima, etc. e que, portanto, é necessário apontar as interdependências entre o meio físico-biológico e os grupos humanos" (PEREIRA, 2009, p. 54).

${ }^{2}$ É através do "materialismo histórico enquanto teoria que considera simultaneamente a relação do homem com a natureza e a relação do homem com o homem" que o marxismo possibilitou à geografia a superação da antinomia sociedade/natureza, uma vez que "[...] a história é um processo de desnaturalização em que o homem, ao transformar a natureza, transforma-se, e que, independe do modo ou forma como os homens produzem seus meios de vida, existe e
} 
Como o acontecer no espaço não se dá de forma homogênea, impõe-se a noção de escala, isto é, de fração do espaço dentro do espaço total. Isto não quer dizer que o acontecer em um lugar é indiferente ao acontecer em um outro lugar, justamente porque, qualquer que seja este acontecer, ele sempre será produto do movimento da sociedade total. A ideia de totalidade é central, bem como a necessidade de sua cisão para que não caiamos no erro da análise do todo pelo todo. Justamente porque o tempo do modo de produção é universal ${ }^{3}$, a categoria de formação social busca analisar como se arranja de forma concreta os diferentes modos de produção num espaço particular em seu desenvolvimento desigual e combinado. O modo de produção, com isso, é a possibilidade de realização, e a formação social, a possibilidade realizada.

Deste modo,

A localização dos homens, das atividades e das coisas no espaço explica-se tanto pelas necessidades externas, aquelas do modo de produção puro, quanto pelas necessidades internas, representadas essencialmente pela estrutura de todas as procuras e a estrutura de classes, isto é, a formação propriamente dita. (SANTOS, 1979, p. 14)

Entendemos que a categoria atinge maior maturidade com Milton Santos, quando se é atribuído com maior solidez o papel do espaço enquanto instância social ${ }^{4}$ — denominando-o de formação socioespacial ${ }^{5}$ - , uma vez que "todos os processos que juntos, formam o modo de produção (produção propriamente dita, circulação, distribuição, consumo) são histórica e espacialmente determinados num movimento de conjunto" (SANTOS, 1979, p. 14).

No que se refere a Teoria da Dualidade Básica, esta designa a "coexistência de relações de produção próprias de diferentes modos fundamentais de produção, agrupadas em 'polos' — interno e externo - em união dialética, isto é, em oposição e conflito" (RANGEL, 2005c, p. 633). Em outras palavras,

existirá sempre um intercâmbio entre o homem e a natureza. É nesse contexto que se situa a afirmação de que é pelo trabalho que o homem produz a sua existência" (PEREIRA, 2009, pp. 75-76).

3 "Los esquemas históricos no carecen de valor como instrumentos de investigación y bases para reunir los caracteres comunes de determinada formación social. Son, por el contrario, imprescindibles en el proceso de generalización y abstracción, pero siempre que se vea en ellos nada más que la clasificación abstracta de una realidad riquísima en matices y se tenga presente el mundo de contradicciones que hierve debajo de ellos" (PUIGGRÓS, 1965).

${ }^{4}$ A característica principal que lhe atribuiria a condição de ser uma instância social seria o fato deste ser uma estrutura subordinada-subordinante, ou se preferir, uma inércia-dinâmica. Isso significa dizer que, do ponto de vista de suas qualidades funcionais, o espaço representaria o reflexo da intencionalidade da sociedade sobre ele. Porém, do ponto de vista de suas qualidade sistêmicas, o espaço seria um condicionante das demais estruturas sociais (SANTOS, 2012, pp. 180-181). O espaço, portanto, não é somente um mero palco da atividade humana, mas sim uma união dialética entre sociedade e natureza, indissociáveis entre si.

${ }^{5} \mathrm{O}$ professor Armen Mamigonian explica que: "Milton Santos, no entanto, percebeu que formação social e geografia humana não coincidem completamente, menos pelas teorias que embasam aquela categoria marxista e esta área do conhecimento acadêmico do que pela prática indispensável de localização da geografia, nem sempre usada nos estudos de formação social, daí ter proposto a categoria “formação socioespacial”" (MAMIGONIAN, 1996, p. 204). 
[...] a coexistência da realidade "antiga" com a "nova" — a contemporaneidade do não coetâneo, por assim dizer - não é uma simples superposição, mas uma oposição. As duas realidades reagem uma sobre a outra e se modificam mutuamente. Além disso, não constituem duas coisas separadas, mas uma realidade complexa única. Para usar a linguagem hegeliana, os contrários estão em unidade dialética. (RANGEL, 2005a, p. 207)

A ideia de dualidade é comumente associada ao pensamento da CEPAL, no entanto, a dualidade rangeliana e o dualismo cepalino são radicalmente distintos. Ao analisar a crítica de Francisco de Oliveira (1988) em sua obra A Economia Brasileira: Crítica à Razão Dualista, endereçada ao modelo cepalino, torna-se claro que muitos dos erros cometidos por ele, não são repetidos pelo pensamento de Rangel. A natureza do dualismo cepalino diz respeito oposição mecanicamente separada de um setor "atrasado" e um setor "moderno". Porém, na realidade, o que acontece é "uma simbiose e uma organicidade, uma unidade de contrários, em que o chamado 'moderno' cresce e se alimenta da existência do 'atrasado"' (Ibidem,p. 12). Ao fim e ao cabo, o autor citado parece se aproximar ainda mais da dualidade rangeliana quando afirma que "assim, dá-se uma primeira 'especificidade particular' do modelo brasileiro, pois, ao contrário do 'clássico' sua progressão não requer a destruição completa do antigo modo de acumulação" (Ibidem, p. 41), explicitando a existência de diferentes modos de produção numa mesma formação social, assim como diz Ignácio Rangel. Da mesma forma acontece com a crítica feito por M. Santos à perspectiva dualista, propondo a bipolaridade ao invés do dualismo, a fim de superar essa separação entre dois setores ditos antagônicos, pois “(...) esses dois setores 'representam o funcionamento de uma só sociedade, da qual os dois polos são parte integrante' [...]'esses dois polos tendo a sua origem no curso de um mesmo processo histórico"” (SANTOS, 2008, p. 55). Mais uma vez, coincide-se muito com o pensamento de Rangel, até mesmo nas nomenclaturas (polo interno e polo externo da dualidade básica).

Conforme aponta o historiador Eric Hobsbawm para a necessidade de distinção entre o processo de conexão da periferia com o sistema capitalista e a criação de estruturas econômicas características do capitalismo moderno (HOBSBAWM, 2017, p. 106), visto que o primeiro não suscitou o surgimento imediato do segundo, torna-se necessário o rompimento com perspectivas circulacionistas para uma análise rigorosa da formação socioespacial pois, entendendo a fase do capitalismo comercial como um capitalismo consolidado, estas consideram capitalista “[...] qualquer país que mantenha relações comerciais na esteira do mercado mundial unificado capitalista, independente das formas de produção internas em cada país", sendo portanto, o "suprassumo da negação do processo como ente histórico/filosófico e, consequentemente, da categoria de modo de produção [grifo do autor] (JABBOUR, 2012, p. 92). Consideramos que Marx já havia assinalado a solução para este problema em seu texto sobre $A$ assim chamada acumulação primitiva, quando diz que: 
A Idade Média havia legado duas formas distintas de capital, que amadureceram nas mais diversas formações socioeconômicas e, antes da era do modo de produção capitalista [grifo nosso], já valiam como capital quand même [em geral]: o capital usurário e o capital comercial. (MARX, 2017, p. 820)

Existe, portanto, uma confusão entre economia mercantil e capitalismo. Isso se dá pois o capitalismo pressupõe uma economia mercantil, mas nem todas as economias mercantis são capitalistas, uma vez que o modo de produção capitalista se inicia quando esta economia mercantil se encontra em sua etapa de desenvolvimento em que torna-se mercadoria até mesmo a força de trabalho (PUIGGRÓS, 1965).

Para fugir da errônea interpretação circulacionista, Ignácio Rangel subdivide a categoria de relação de produção para as relações de produção interna e externa. Deste modo,

[...] queremos dizer que a fazenda de escravos estava sujeita a duas ordens de leis: as do escravismo e as do capitalismo, e podemos passar a uma observação da máxima importância, porque comum a todas as fases de evolução brasileira, isto é: que essas duas ordens de leis governam, respectivamente, as relações internas e externas da economia. Assim, não basta dizer que o latifúndio é uma economia mista, feudal-capitalista, mas é necessário compreender que é internamente feudal e externamente capitalista. (RANGEL, 2005b, p. 297)

Portanto, evidencia-se a potencialidade interpretativa da Teoria da Dualidade, na medida em que realiza o princípio mais elementar da análise da formação socioespacial, isto é, a articulação entre diferentes modos de produção engendrados em uma unidade de contrários, de forma a superar as perspectivas circulacionistas/dependentistas, que atribuem foco central nas externalidades, através de uma análise que engendra tanto a esfera da produção quanto da circulação. Bem como supera os modelos cepalinos que se atém a visão nada dialética da contínua reprodução do arcaico em antagonismo ao moderno, e explicita a progressividade da história sob a especificidade de um desenvolvimento desigual e combinado da periferia do sistema capitalista.

\section{A FORMAÇÃO SOCIOESPACIAL DA AMÉRICA LATINA}

As condições naturais e humanas encontradas pelos europeus na América Latina exercera fundamental influência na conformação das atividades produtivas ali realizadas. O núcleo da colonização espanhola, por exemplo, se deu nas regiões do planalto andino e mexicano, onde havia sociedades sedentarizadas e com grande densidade demográfica, bem como conhecimento acerca dos recursos minerais presentes, o que facilitou a implantação direta de relações de produção feudais e a exploração da prata (DONGHI, 1974, p. 29; PEREIRA, 2012, p. 5). Na América Portuguesa, onde prepondera o nomadismo das populações pré-colombianas e climas referentes à zona térmica tropical, passou-se a produzir cana-de-açúcar através da mão-de-obra escrava. 
Durante os séculos XVI e XVII, a Europa viu se formar, no seio de sua sociedade feudal, elementos do que futuramente identificaria como sendo a fase do capitalismo comercial ou mercantil, isto é, o período de transição do feudalismo para o capitalismo, onde coexistem elementos feudais com elementos capitalistas, representados pela expansão comercial e pelas pilhagens coloniais ${ }^{6}$. Durante este período o capital comercial incorporou o papel de articulador entre o centro e a periferia, e assim "as formações sócio-espaciais periféricas eram compostas de dois setores: o capital mercantil europeu presente na colônia e na metrópole e as estruturas produtivas internas que sozinhas não conseguiam definir um modo de produção" (MAMIGONIAN, 2000, pp. 23-24). Este conjunto de dois setores econômicos constituem "formações complexas, que combinam dialeticamente várias estruturas elementares" (RANGEL, 1968,p. 7). Portanto, as economias latino-americanas possuíam um caráter dual, em que suas relações de produção externas eram capitalistas, e as internas, précapitalistas (Idem, 2005b, p. 298).

Evidenciando o caráter feudal dos Estados colonizadores ibéricos, não é de se surpreender que o "o próprio desenvolvimento do capitalismo em escala mundial gerou ou regenerou em vários lugares e em vários momentos relações sociais dependentes que não são capitalistas” (HOBSBAWM, 2017, p. 106), isto é, a América Latina fora organizada sob um enquadramento jurídico e econômico próprio do feudalismo ${ }^{7}$ na medida em que "ação individual, que serviu de base à ocupação dos territórios americanos, realizou-se dentro de um quadro contratual estritamente delimitado pelo Estado espanhol e português" (FURTADO, 1978, p. 18). Deste modo, prevaleceu "o princípio de que as terras somente seriam concedidas àqueles que dispusessem de meios para explorá-las de forma a produzir um excedente monetizável a ser parcialmente transferido para a Corôa” (Ibidem, p. 79).

A partir das concessões de terras pelas coroas ibéricas aos donatários — através das encomiendas e haciendas na América espanhola; e das capitanias hereditárias e sesmarias na América portuguesa - , construía-se aquilo que se chama de anfiteatro enfiteuse. Isto é, o edifício no qual ergue-se as relações de produção feudais, onde nos patamares superiores, encontramos as relações

\footnotetext{
${ }^{6} \mathrm{Na}$ maioria dos países europeus, os elementos capitalistas que surgiam no seio da sociedade feudal estavam restritos a estrutura econômica, enquanto que a superestrutura jurídico-política era estritamente feudal. Porém, especificamente em Portugal, o capital comercial participa muito fortemente da superestrutura do Estado, numa espécie de coalizão entre os comerciantes e a aristocracia feudal, em que os comerciantes, ao invés de se contraporem a ordem feudal, se aliam à ela. Nas palavras de Celso Furtado: "Enquanto nos países do continente os interesses de duas classes se desenvolviam antagônicos, servindo de exploração do jogo dos reis que se afirmavam como poder absoluto, em Portugal cedo se desenvolveu um espírito de colaboração entre as duas classes dominantes, colaboração essa que deu lugar à formação de uma política nacional que seria coerentemente seguida levando o Reino ao fastígio de seu poder e riqueza na época em que as outras monarquias européias lutavam pela consolidação de suas fronteiras nacionais" (FURTADO, 2001, p. 33).

${ }^{7}$ A partir desta constatação, se compreende com mais clareza a passagem contida na biografia de A. Von Humboldt, escrita por Andrea Wulf (2016), quando diz: "E assim como Humboldt havia afirmado em Ensaio político sobre o reino da Nova Espanha que os vícios do governo feudal foram transmitidos do Hemisfério Norte para o Hemisfério Sul, Bolívar agora comparava o jugo colonial sobre suas colônias a 'uma espécie de posse feudal'” (p. 230).
} 
entre o barão e o rei, relações de suserania e vassalagem; e nos patamares inferiores, relações entre o barão e o servo de gleba. Deste modo, na América espanhola

Os conquistadores e seus sucessores orientaram-se predominantemente para a agricultura, sobretudo como encomenderos, dos quais deviam receber os tributos que, em todos os casos, os vassalos indígenas deviam à Coroa; posteriormente, com frequência cada vez maior a partir do colapso demográfico do século XVII, passaram a ser proprietários de terras recebidas através de doação real. (DONGHI, 1974, pp. 12-13)

Neste sentido, “o encomendero, em razão da tutela que exercia sobre um grupo de população, passava a exercer privadamente funções de direito público, o que o colocava socialmente em posição somente comparável à do senhor feudal” (FURTADO, 1978, p. 19).

Posteriormente, o sistema cuja base era a encomienda fora substituída pela hacienda, unidade de produção agrária dirigida pelos espanhóis. Esta última consiste em uma empresa comercial orientada essencialmente para os consumidores externos (DONGHI, 1974, p. 13). Sobre ela, duas proposições podem ser feitas com segurança

Em primeiro lugar, em suas relações externas, não eram feudais.(...) Sobretudo, o objetivo de uma fazenda era a produção para a venda em um mercado supralocal e, consequentemente, o lucro. (...) Em segundo lugar, a organização interna e as relações das fazendas só podem ser descritas como feudais. (HOBSBAWM, 2017, pp. 113-115)

Por outro lado, a diferença do desenvolvimento das forças produtivas entre as sociedades précolombianas da América portuguesa e espanhola neste período acabou por suscitar um conteúdo préfeudal no enquadramento jurídico do Brasil colonial, responsável pelo escravismo ${ }^{8}$. Deste modo, a colonização brasileira não engendrou o anfiteatro enfiteuse de forma completa, com suas relações Corôa-Barão e Barão-Servo, mas estabeleceu apenas os andares superiores deste edifício jurídico. Isto é, entre os donatários das concessões de domínio útil da terra e a Coroa portuguesa estabeleceuse relações de suserania e vassalagem ${ }^{9}$, ao passo que, entre estes vassalos da Coroa e os trabalhadores diretos, estabeleceu-se relações escravistas (RANGEL, 2005e, p. 657). Esta situação muda quando se concretiza na superestrutura jurídico-política do Estado a defesa da propriedade privada da terra, através da Lei de Terras (1850), possibilitando a monopolização desta pelos proprietários de

\footnotetext{
${ }^{8} \mathrm{Na}$ América espanhola, onde a população nativa, principalmente sob o modo de produção asiático, atingira certo grau de desenvolvimento capaz de praticar uma agricultura estável, bastava controlar a terra para que fosse possível controlar a população. Por outro lado, na América portuguesa, onde não havia estrutura social estável e vivia-se sob um modo de produção comunista primitivo, impuseram-se relações escravistas de produção. (RANGEL, 2005b, p. 308).

${ }^{9}$ Segundo Caio Prado Jr., "o Rei conservará apenas direitos de suserania semelhantes aos que vigoravam na Europa feudal. Em compensação, os donatários das capitanias arcariam com todas as despesas de transporte e estabelecimento de povoadores" (PRADO JUNIOR, 1987, p. 17)
} 
escravos $^{10}$. Trinto e oito anos depois, estes mesmos escravos se tornam totalmente libertos (Lei Áurea - 1888), porém, sem a condição de acesso às terras já monopolizadas pelos novos latifundiários, antigos senhores de escravos. Deste modo, esta mão-de-obra torna-se agregada dos grandes latifúndios, onde circulam rendas trabalho e rendas produto — rendas essencialmente feudais ${ }^{11}$. Jacob Gorender assinala que:

O fazendeiro podia ser comerciante, podia ser financiador de outros fazendeiros, mas isso não mudava o modo de produção dentro da fazenda dele [grifo nosso]. Como fazendeiro, era um grande proprietário de terra que vivia fundamentalmente da renda da terra e não do lucro do capital, contendo essa renda da terra aspectos definidamente pré-capitalistas, além de predominar sobre o lucro do parco capital aplicado na atividade propriamente agrícola. (GORENDER, 1987, p. 38)

Portanto, durante todo o período colonial na América espanhola, e a partir da metade do século XIX em toda a América Latina, surgem relações interpessoais e extra-econômicas de tipo servil. Este polo interno pré-capitalista, no entanto, coexiste com um polo externo capitalista, o que promove a especificidade da formação social latino-americana.

Com a Revolução Industrial inglesa e a posterior Revolução Francesa, ambas no fim do século XVIII, o capitalismo tratava de se consolidar, agora em sua fase industrial. Ele que "na forma de mercantilismo, havia sido mero instrumento a serviço de uma economia feudal, emergia como a forma dominante e revolucionava toda a economia mundial" (RANGEL, 2005b, p. 309). Deste modo, à luz dos fatores objetivamente estratégicos dos modos fundamentais de produção (escravismo: o homem; feudalismo: a terra; capitalismo: o capital) ${ }^{12}$, podemos observar que a formação social latinoamericana, da qual tinha o meio natural como determinante geográfico — visto que a terra (América espanhola) e o escravo (América portuguesa) eram os fatores objetivamente estratégicos — passou a

\footnotetext{
${ }^{10}$ Nota-se que ganha centralidade estratégica o monopólio da terra. Esta, "menos para usar do que para monopolizar, compelindo, assim, a mão-de-obra disponível a servi-lo” (RIBEIRO, 2007, p. 217).

${ }^{11}$ Como demonstra Darcy Ribeiro: “[...] com a libertação dos escravos aumentam extraordinariamente, pela absorção de toda a antiga massa de negros forros como procedimento utilizado pelo patronato para jungi-la ao trabalho e fixá-la nas fazendas como mão-de-obra sem fazê-la assalariada. (...) Sua condição é a de arrendatários de tratos de terra mediante o pagamento da metade (meeiros) ou de uma terça parte (terceiros) das colheitas que obtêm" (RIBEIRO, 2007, p. 226). No mesmo caminho segue E. Hobsbawm que aponta que "métodos neofeudais também podiam ser utilizados, em certa medida (como no Brasil), para preencher as lacunas deixadas pela abolição da escravatura” (HOBSBAWM, 2017, p. 128)

12 "Pondo de parte o primeiro e o último dos modos fundamentais de produção [comunismo primitivo e socialismo], dado que, em ambos o corpo social comanda todos os fatores de produção, nos demais a hegemonia cabe à classe detentora do domínio do fator objetivamente estratégico. E é isso o que caracteriza o modo de produção e a formação social que sobre ele se edifica" (RANGEL, 2005c p. 631).
} 
ser pressionada externamente pelo novo ritmo de produção do meio técnico inglês, do qual tinha o capital como fator objetivamente estratégico ${ }^{13}$.

Diferentemente dos países centrais que em sua maioria engendraram o capitalismo em seu interior, a periferia do sistema capitalista se conecta com o modo de produção mais avançado de forma exógena. Com isso, levando às últimas consequências o postulado marxiano presente no prefácio da Contribuição à crítica da economia política que diz que um novo modo de produção surge quando o desenvolvimento das forças produtivas entra em contradição com as relações de produção vigentes (MARX, 2008, pp. 49-50), Rangel entende que as rupturas na América Latina podem ter origem tanto nas relações internas quanto nas relações externas de produção. Este período de deslocamento do centro dinâmico do sistema capitalista dos representantes do capitalismo mercantil, Espanha e Portugal, para o nascente capitalismo industrial inglês, gera a onda de insurreições que atinge o continente como um todo, com, por exemplo, as independências da Argentina (1815), do México (1821) e do Brasil (1822) (PEREIRA, 2012). Portanto, estas insurreições são interpretadas neste artigo como manifestações da contradição do desenvolvimento das forças produtivas internas da América Latina com suas relações de produção externas, sobretudo os entraves dos quais o aparelho de intermediação comercial da metrópole exercia sobre colônia.

A partir de sua consolidação, o sistema capitalista incorpora uma nova dinâmica de desenvolvimento. Esta nova dinâmica consiste em ciclos de acumulação com duração média de meio século, em que sua primeira fase (a) - isto é, seus primeiros vinte e cinco anos, aproximadamente — se torna um período de expansão econômica, e sua segunda fase (b) — os vinte e cinco anos seguintes - um período de depressão. Estes ciclos mantém estreita relação com as inovações tecnológicas, uma vez que, quando as inovações são postas a serviço do mercado (máquina a vapor, energia elétrica, etc.), estas proporcionam superlucros para as grandes empresas detentoras da tecnologia nova, fazendo com que a economia se expanda. Com o tempo, as inovações vão se difundindo para as demais empresas e a taxa média de lucro se comprime, abrindo uma fase recessiva da economia (KONDRATIEFF, 1935). Estas flutuações foram teorizadas pela primeira vez em 1926 através dos estudos de estatística econômica de Nicolai Kondratieff, e, por este motivo, tais ciclos são denominados de ciclos de Kondratieff ou ciclos longos.

Do ponto de vista da periferia do sistema, estes ciclos são cruciais no que diz respeito ao desenvolvimento econômico na medida em que, com a economia mundial em expansão, a procura, por parte do centro, por produtos primários da periferia aumenta, inserindo mais veementemente ela na divisão internacional do trabalho. Ao passo que, com a economia em depressão, a periferia, não

\footnotetext{
${ }^{13}$ Reserva-se o conceito de "meio técnico à fase posterior à invenção e ao uso das máquinas, já que estas, unidas ao solo, dão toda uma nova dimensão à respectiva geografia" (SANTOS, 2017 p. 234).
} 
tendo meios para importar aquilo que antes era importado, passa a realizar um processo de substituição de importações, isto é, começa a produzir internamente aquilo que antes era adquirido no exterior (MAMIGONIAN, 2000, p. 29).

No que se refere a sua organização produtiva, vemos que "desenvolvimento da economia capitalista moderna mundial penetrou inevitavelmente em numerosas sociedades com relações predominantemente feudais", (HOBSBAWM, 2017, pp. 105-106). O prefácio escrito por Ignácio Rangel na obra Dialética do Subdesenvolvimento, de R. Losada Aldana, explana claramente esta questão:

Assim é que o capitalismo, vitorioso em seu combate de morte com o feudalismo europeu, em fins do século XVIII, levou todo o século XIX, em toda a periferia subdesenvolvida que vivia nas condições de comunismo primitivo, da escravidão ou do 'modo de produção asiático' - a suscitar a criação de muito mais feudalismo do que o destruído nos países de vanguarda. Somente assim foi possível organizar o espaço, incluindo o mundo inteiro no seu sistema. Objetivamente, portanto, esse feudalismo era uma forma de organização da produção capitalista mundial, sem deixar, porém, de ser feudalismo. (RANGEL, 1968, p. 5)

III

Na segunda metade do século XIX o capitalismo inicia sua fase monopolista ou imperialista, quando bancos e indústrias se fundem, formando o capital financeiro (LENIN, 2012). Com a profunda financeirização da economia e a forte tendência de superprodução e subconsumo, o capitalismo acaba por cair na mais severa crise de sua história, em 1929, inserida na fase b do terceiro Kondratieff. Antes disso, o feudalismo no polo interno latino-americano se exacerbara, conforme aponta Hobsbawm:

\begin{abstract}
Uma consideração mais séria talvez possa ser feita para o período em que a América Latina tornou-se parte de uma economia imperialista mundial em expansão, ou seja, do final do século XIX até a crise mundial dos anos 1930. Durante esse período, o incentivo para prosseguir a expansão da produção agrária utilizando os recursos disponíveis para uma economia de hacienda tradicional - expansão das propriedades, expropriação de terras camponesas e comunitárias, coerção não econômica, trabalho servil, dívida-peonagem etc. - estava em seu máximo, o apoio dos governos a plantadores e fazendeiros, locais e estrangeiros, era quase ilimitado, a resistência da população rural estava em baixa e as tensões que se fariam sentir posteriormente em movimentos revolucionários e outros ainda estava se acumulando. (HOBSBAWM, 2017, p. 128)
\end{abstract}

A crise de 1929 provoca uma intensa queda nas importações européias e estadunidenses, o que faz com que, na América Latina, as classes agroexportadoras - ligadas ao decadente capital inglês - se enfraqueçam, dando lugar aos latifundiários e industriais ligados ao mercado interno e ao desenvolvimento endógeno, com o apoio financeiro norte-americano, que estava em ascensão (MAMIGONIAN, 2000, p. 2).

Entre 1930 e 1980, a América Latina vive o seu mais intenso crescimento hacia dentro, na feliz expressão do economista argentino Raul Prebish. Este desenvolvimento foi capaz de se manter 
constante mesmo após o início da fase expansiva de 1948, pois neste período pós-guerra as trocas comerciais passam a ter maior fluxo entre os próprios países desenvolvidos, funcionando como um entrave às exportações periféricas e, consequentemente, às importações também. (RANGEL, 2005d, p. 698; FURTADO, 1978, p. 61) Neste espaço de tempo, tivemos experiências em planejamento e financiamento econômico, como a CORFO no Chile (1939), o BNDE no Brasil (1952) e a Corporação de Fomento Andino, mais tarde. Surgiram órgãos de pesquisa em diferentes níveis e setores, como a CEPAL, universidades como a UNAM e a USP, e pesquisas agrícolas como a EMBRAPA; além da implantação e expansão de grandes empresas estatais em áreas estratégicas, como a de petróleo: YPF, PEMEX, Petrobras, PDVSA, etc. (MAMIGONIAN, 2006, p. 2).

Posteriormente à segunda crise do século XX, em 1973, começando a fase b do quarto Kondratieff, inicia-se uma reação estadunidense com forte caráter imperialista gerando a chamada crise da dívida, que atingiu a América Latina como um todo e consistiu no aumento da taxa de juros pela política monetarista de Paul Volcker, presidente do banco central estadunidense da época, visando o pagamento voraz dos juros das dívidas externas e a abertura dos mercados internos, favorecendo as empresas industriais e de serviços do centro do sistema, sobretudo norte-americanas. Com isso, a onda nacional-desenvolvimentista latino-americana é derrotada, através de um estrangulamento comercial e financeiro, abrindo-se portas ao neoliberalismo no continente. $\mathrm{O}$ resultado disso foi uma brutal desindustrialização e desemprego em massa. A abertura dos mercados nacionais latino-americanos às importações, com seus enormes déficits comerciais somados ao fluxo de capitais estrangeiros especulativos para as bolsas, atraídos pelos juros altos, provocou dumping na produção interna e consequente recessão interna (MAMIGONIAN, 1999, p. 148).

O século XXI começou com um leve respiro econômico para a América Latina, com a chegada ao poder de governos progressistas, porém este respiro se mostrou muito incipiente. Atualmente, o continente recebe mais uma investida neoliberal com fortes flexibilizações trabalhistas e ataques aos direitos sociais, como é o caso do golpe de Estado no Brasil e da tentativa de prolongamento do tempo de contribuição à previdência no Brasil e na Argentina, países que recentemente se entregaram ao receituário neoliberal.

\section{CONCLUSÃO}

Este artigo buscou evidenciar que, desde o princípio da colonização latino-americana gestaram-se dois polos em união dialética que conformam as bases de sua formação socioespacial. Estes dois polos, interno e externo, dizem respeito a penetração gradual do capitalismo impondo-se de forma exógena e que, como sendo um processo, implica num período de transição em que coexistem diferentes estruturas econômicas. 
Partindo dos princípios próprios da categoria de formação socioespacial, isto é, combinações de diferentes relações de produção e forças produtivas geograficamente localizadas, Rangel contribui para a sua complementação no que diz respeito a periferia do sistema capitalista e, sobretudo, à realidade latino-americana. A subdivisão da categoria de relação de produção permite uma análise que compreenda a distinção da esfera da produção e da circulação numa mesma união dialética que compõem a formação socioespacial, afastando-se das interpretações que atribuem total determinação à circulação em sua caracterização. Com isso, capacita-se para explicar a realidade latino-americana em sua totalidade, seus fatores internos e externos, abarcando suas peculiaridades próprias de uma formação complexa, isto é, que conecta-se com o modo de produção mais avançado de forma exógena.

\section{REFERÊNCIAS}

DONGHI, H. História da América Latina. 1. ed. Rio de Janeiro: Editora Paz e Terra, 1974. 492p. FURTADO, C. A economia latino-americana. 2. ed. São Paulo: Companhia Editora Nacional, 1978. 536p. FURTADO, C. Economia colonial no Brasil nos séculos XVI e XVII. São Paulo: Ed. Hucitec Ltda., 2001. 200p.

GORENDER, J. Gênese e desenvolvimento do capitalismo no campo brasileiro. Porto Alegre: Mercado Aberto, 1987. 30p.

HOBSBAWM, E. Viva la revolución: a era das utopias na América Latina. 1. ed. São Paulo : Companhia das Letras, 2017. 560p.

JABBOUR, E. China hoje: projeto nacional, desenvolvimento e socialismo de mercado. 1. ed. São Paulo: Anita Garibaldi, 2012. 456p.

KONDRATIEFF, N. Los grandes ciclos de la vida económica. The review of economic statistics. v. 17, n. 6 , p. 105-115, 1935.

LENIN, V. L. Imperialismo, estágio superior do capitalismo: ensaio popular. 1. ed. São Paulo : Expressão popular, 2012. 171p.

MAMIGONIAN, A. A geografia e "a formação social como teoria e como método". In: SOUZA, M. A. A. (Org.). O mundo do cidadão, um cidadão do mundo. São Paulo: Hucitec, 1996.

MAMIGONIAN, A. A América Latina e a economia mundial: notas sobre os casos chileno, mexicano e brasileiro. Geosul, Florianópolis, v. 14, n. 28, p. 139-151, 1999.

MAMIGONIAN, A. Teorias sobre a industrialização brasileira. Florianópolis: Cadernos Geográficos, 2000. 49p.

MAMIGONIAN, A. Qual o Futuro da América Latina?. In: LEMOS, A. I. G.; SILVEIRA M. L.; ARROYO, M. (Org.). Questões territoriais na América Latina. Ed. Clacso, 2006.

MAMIGONIAN, Armen. Visão geográfica do Brasil atual: estado, crises e desenvolvimento regional. Disponível em: <http://geografiaeconomicaesocial.ufsc.br/files/2016/04/Geografia-do-Brasil-hoje.pdf>. Acesso em: 03 nov. 2018.

MARX, K. Contribuição à crítica da economia política. 2. ed. São Paulo: Expressão popular, 2008. 288p. 
MARX, K. O Capital: crítica da economia política: livro I: o processo de produção do capital. 2. ed. São Paulo: Boitempo, 2017. 894p.

OLIVEIRA, F. Economia brasileira: crítica à razão dualista. Petrópolis : Vozes Ltda, 1988. 150p.

PEREIRA. R. M. F. A. Da geografia que se ensina à gênese da geografia moderna. 4. ed. Florianópolis: Editora da UFSC, 2009. 128p.

PEREIRA. R. M. F. A. Formações socioespaciais latinoamericanas: da gênese às rupturas decorrentes do processo de independência, no início do século XIX. In: COLOQUI INTERNACIONAL DE GEOCRÍTICA. 12., 2012. Bogotá, Anais... Bogotá, 2012.

PRADO JUNIOR, C. História Econômica do Brasil. 37. ed. Brasília: Editora Braziliense, 1987. 365p.

PUIGGRÓS, R. Los modos de producción en iberoamérica. In: Debate Rodolfo Puiggrós - André Gunder Frank. Ciudad de México : El Día, 1965.

RANGEL, I. Prefácio à Edição Brasileira. Dialética do Subdesenvolvimento. São Paulo: Editora Paz e Terra, 1968.

RANGEL, I. Desenvolvimento e projeto. Obras Reunidas/Ignácio Rangel. Rio de Janeiro: Ed. Contraponto, 2005a. 742p.

RANGEL, I. Dualidade Básica da Economia Brasileira. Obras Reunidas/Ignácio Rangel. Rio de Janeiro: Ed. Contraponto, 2005b. 742p.

RANGEL, I. Dualidade e "escravismo colonial”. Obras Reunidas/Ignácio Rangel. Rio de Janeiro: Ed. Contraponto, 2005c. 742p.

RANGEL, I. Economia: Milagre e Antimilagre. Obras Reunidas/Ignácio Rangel. Rio de Janeiro: Ed. Contraponto, 2005d. 742p.

RANGEL, I. História da dualidade brasileira. Obras Reunidas/Ignácio Rangel. Rio de Janeiro: Ed. Contraponto, 2005e. 742p.

RIBEIRO, D. As Américas e a civilização: o processo de formação e causas do desenvolvimento desigual dos povos americanos. 1. ed. São Paulo: Companhia das Letras, 2007. 527p.

SANTOS, M. Sociedade e Espaço: a formação social como teoria e como método. In: Espaço e sociedade. Petrópolis: Vozes, 1979. p. 81-99.

SANTOS, M. O espaço dividido: os dois circuitos da economia urbana dos países subdesenvolvidos. 2. ed. São Paulo: Editora da Universidade de São Paulo, 2008. 440p.

SANTOS, M. Por uma geografia nova: da crítica da geografia a uma geografia crítica. 6. ed., São Paulo : Editora da Universidade de São Paulo, 2012. 288p.

SANTOS, M. A natureza do espaço: técnica e tempo, razão e emoção. 4. ed. São Paulo : Editora da Universidade de São Paulo, 2017. 388p.

WULF, A. A invenção da natureza: a vida e as descobertas de Alexander Von Humboldt. 1. ed. São Paulo : Planeta, 2016. 600p. 